\title{
Corrosion Characterization of Friction Stir Weld Joints of Dissimilar Aluminum Alloys
}

\author{
Ramesha $\mathrm{K}^{1,3 *}$, P D Sudersanan ${ }^{1}$, Santhosh $\mathrm{N}^{2}$, Sasidhar Jangam ${ }^{3}$ \\ ${ }^{1}$ Department of Mechanical Engineering, Dr. T Thimmaiah Institute of Technology, KGF. \\ ${ }^{2}$ Department of Mechanical Engineering, M.V.J. College of Engineering, Bangalore, \\ ${ }^{3}$ Department of Mechanical and Automobile Engineering, School of Engineering and Technol- \\ ogy, CHRIST (Deemed to be University), Bangalore, \\ ramesha.kra@gmail.com
}

\begin{abstract}
Friction Stir Welding is a solid state welding processused in aerospace, automobile and machine tool industry. However, corrosion of the friction stir weld zones is still a major drawback that needs to be addressed immediately; hence the current work focuses on the corrosion characterization of the friction stir weld joints of dissimilar aluminium alloy. In the present research, friction stir welding is carried out at different set of parametric conditions and the weld joints are characterized for weight loss corrosion in sodium chloride saline medium. The friction stir weld joints of dissimilar aluminium alloys are obtained using three sets of process parameters viz., tool profiles of straight cylinder, taper cylinder, and straight triangular; tool rotational speed of $800 \mathrm{rpm}$, $1000 \mathrm{rpm}$, and $1200 \mathrm{rpm}$; tool feed rate of $100 \mathrm{~mm} / \mathrm{min}, 120 \mathrm{~mm} / \mathrm{min}$, and 140 $\mathrm{mm} / \mathrm{min}$; tool offset of $0.5 \mathrm{~mm}, 0 \mathrm{~mm}$, and $-0.5 \mathrm{~mm}$. The corrosion characterization is carried out for friction stir weld joint using immersion tests. The results give an overview of the variation in the corrosion with time, and the effect of process parameters on the corrosion behavior of weld joints.
\end{abstract}

Keywords:Corrosion, Characterization, Friction Stir Welding, Dissimilar, Aluminium Alloys, Joints.

\section{$1 \quad$ Introduction}

Aluminium Alloys are profusely used in aircraft and automobiles because of its exceptional properties with respect to formability, and greater strength to weight ratio. However, the major drawback with the use of aluminium alloys in structural applications are related to weldability; henceforth, it is important to develop newer welding techniques that gives high strength welding joints which are corrosion resistant and have minimum weld defects [1]. In this regard, a lot of research is carried out in the field of Friction Stir Welding (FSW) [2]. Friction stir welding (FSW) is a solid-state welding process, developed by "The Welding Institute, (TWI)", in the year 1991. In this process, the joining of workpieces is accomplished by the FSW tool, [11] which creates the weld joint by plastic process [3][10]. The technique of FSW improves the strength characteristics of the weld joint; however, the corrosion behaviour of FSW 
joints are a critical aspect of concern, which needs to be studied [4][9]. In this regard corrosion characterization of FSW weld joints of dissimilar aluminium alloys is studied in this research for a prospectus in real-time engineering applications

\section{$2 \quad$ Materials and methods}

Aluminium AA 5052 and Aluminium AA 7075 alloys are used to prepare Friction Stir Weld joints as per the Taguchi's L9 orthogonal array. The material is procured from Perfect Metal Works, Bangalore.

\subsection{Materials - Work-piece}

AA 7xxx and AA 5xxx are light metal alloys which are most commonly used in various structural applications, especially in the field of automobile, naval and aircraft industries. Aluminium AA 7075 is an alloy with zinc as the primary element exhibiting high strength, fracture toughness and resistance to corrosion which is the basic attribute for its use in aerospace structures, while AA 5052 is an aluminium alloy having magnesium as the predominant alloying element with better strength, weldability and anti-corrosive properties used profusely for plate structures especially having its wide scope in aerospace components. The composition of the Aluminium AA 7075 and Aluminium AA 5052 are given in table 1.

\begin{tabular}{|c|c|c|}
\hline $\begin{array}{l}\text { Element } \\
(\%)\end{array}$ & $\begin{array}{r}\text { AA } \\
7075\end{array}$ & $\begin{array}{r}\text { AA } \\
5052\end{array}$ \\
\hline $\mathrm{Al}$ & Bal. & Bal. \\
\hline $\mathrm{Zn}$ & 5.8 & 0.1 \\
\hline $\mathrm{Mn}$ & 0.2 & 0.1 \\
\hline $\mathrm{Si}$ & 0.4 & 0.45 \\
\hline $\mathrm{Cu}$ & 1.6 & 0.1 \\
\hline $\mathrm{Fe}$ & 0.4 & 0.35 \\
\hline $\mathrm{Mg}$ & 2.4 & 2.6 \\
\hline $\mathrm{Ti}$ & 0.1 & - \\
\hline $\mathrm{Cr}$ & 0.25 & 0.2 \\
\hline Others & 0.14 & 0.15 \\
\hline
\end{tabular}

The workpiece is cut into the required size of $170 \times 60 \times 5 \mathrm{~mm}$ as shown in figure 1 , depending upon the available fixture dimensions to hold the workpiece during the FSW Process. 

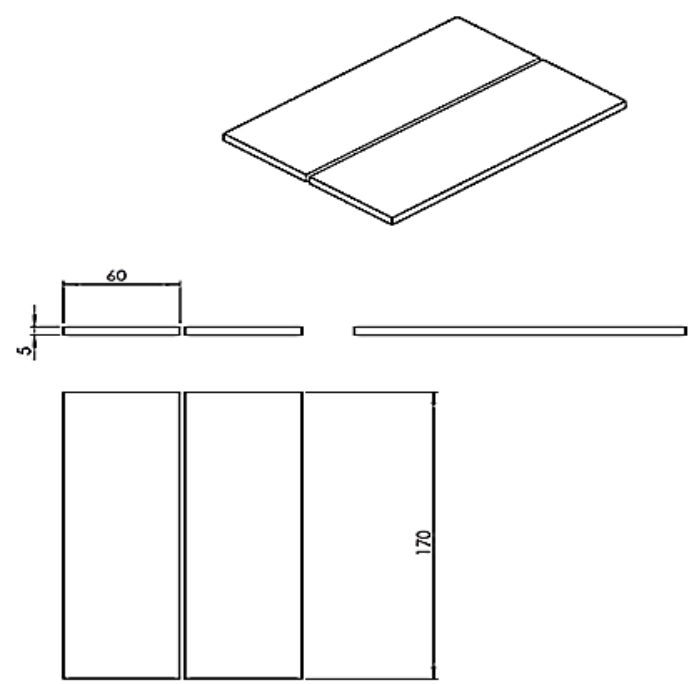

Fig. 1. Schematic of Workpiece dimensions for FSW

\subsection{Materials - FSW Tool}

The friction stir welding is carried out by using a typical non-consumable tool made up of $\mathrm{H} 13$ tool steel with the hardness of $55 \mathrm{HRC}$. The specifications of the tool is given in table 2 . In the current research work, three pin profiles viz., cylindrical, cylindrical taper, and triangular have been considered, the schematic of all the three pin profiles are given in figure 2 .

Table 2.Tool Specifications

\begin{tabular}{llc}
\hline Tool shoulder & \multicolumn{2}{c}{$20 \mathrm{~mm}$ (flat surface) } \\
\hline Tool pin configuration & $\begin{array}{c}\text { Cylindrical, } \\
\text { Taper, and Triangular }\end{array}$ \\
\hline Pin length & $4.8 \mathrm{~mm}$ \\
\hline Pin diameter & Cylindrical & $5 \mathrm{~mm}$ \\
\cline { 2 - 3 } & Triangle & $5 \mathrm{~mm}$ \\
\cline { 2 - 3 } & Taper & $\mathrm{D}=5$ \\
& $\mathrm{~mm} \mathrm{~d}=4$ \\
& $\mathrm{~mm}$ \\
\hline
\end{tabular}



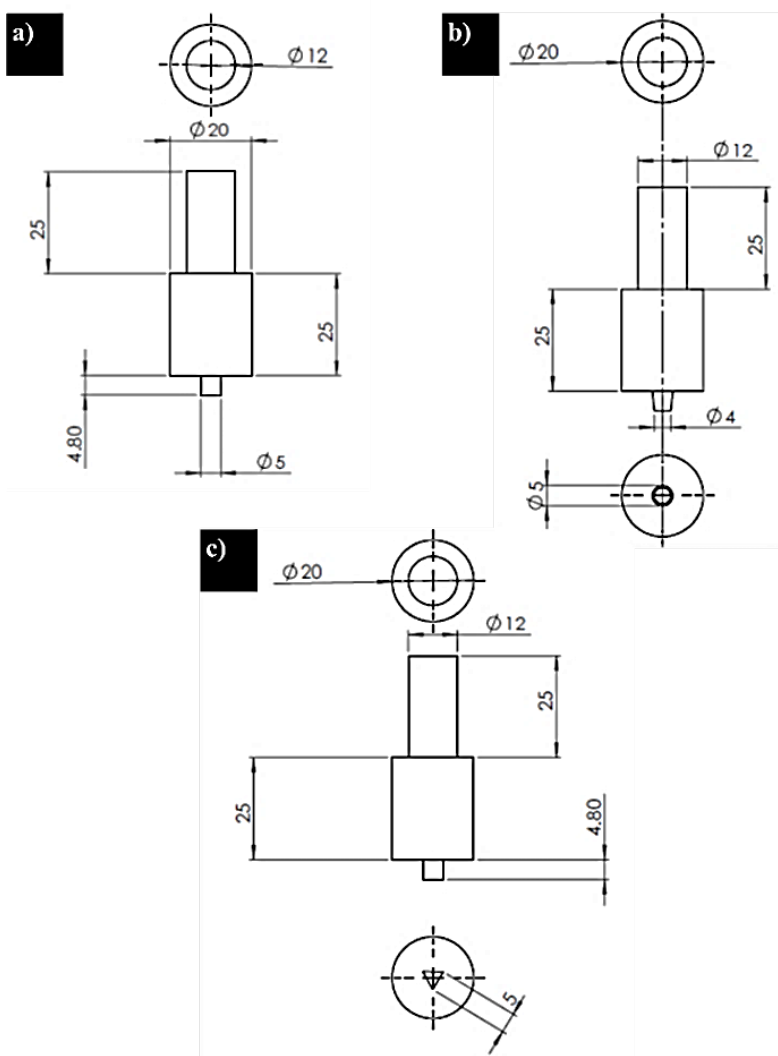

Fig. 2. Schematic of the tool pin profiles (a) Cylindrical (Cyl.), (b) Cylindrical - taper (Cyl. Tp.) and (c) Triangle.

\subsection{Methodology - FSW}

Aluminium AA 7075 and AA 5052 alloys are welded together by friction stir welding process on an ETA make $10 \mathrm{~T}$ model horizontal FSW machine. The process is carried out in accordance with the Design of Experiments (DOE) table framed in accordance with L9 Orthogonal Array (OA) considering Taguchi Design model from Minitab Software. The process parameters considered in present work involved design specific parameters like tool rotational speed $(800,1000$, and $1200 \mathrm{rpm})$, transverse feed ( 80 , 100 , and $120 \mathrm{~mm} / \mathrm{min}$ ) and tool pin configuration (cylinder, cylinder-taper, and triangle). The details of welding parameters and its levels are given in table 3. During the process of welding, AA 7075 is located on the retreating side, while AA 5052 is located on the advancing side. The tool shoulder is plunged into the plates fastened on the unique fixtures clamped on the table of the machine, and the FSW process is carried out in accordance with the Design of Experiments (DOE). 
Table 3. Levels of Parameters for FSW process

\begin{tabular}{|c|c|c|c|c|}
\hline $\begin{array}{l}\text { Sl. } \\
\text { No }\end{array}$ & Parameters & Level 1 & Level 2 & Level 3 \\
\hline 1. & $\begin{array}{l}\text { Rotational } \quad \text { Speed } \\
(\mathrm{rpm})\end{array}$ & 800 & 1000 & 1200 \\
\hline 2. & Feed $(\mathrm{mm} / \mathrm{min})$ & 100 & 120 & 140 \\
\hline 3. & Tool Offset (mm) & -0.5 & 0 & 0.5 \\
\hline 4. & Tool Pin Profile & al Cylindric & $\begin{array}{l}\text { Cylindrical } \\
\text { (Taper) }\end{array}$ & Triangle \\
\hline
\end{tabular}

\subsection{Corrosion characterization}

Corrosion characterization of the weld joints has gained importance due to the immediate need of the globe to conserve the world's metal resources [5]. Corrosion studies of friction stir weld joints of similar and/or dissimilar aluminium alloys have grabbed much attention by research community due to its real-time applications especially in naval and aerospace sectors [6]. Aluminium and its alloys emerged as significant materials in a wide variety of applications. Majority of the previous studies related to corrosion characterization of ferrous and non-ferrous alloys are in acidic and base media but very few or none have investigated in saline $(\mathrm{NaCl})$ media [7]. Hence this gap in available literature has given scope for evolving interest in potentio-dynamic corrosion characterization of the friction stir weld specimens in sodium chloride $(\mathrm{NaCl})$ media. The methodology followed during the static immersion weight loss corrosion technique is represented by the schematic block diagram in figure 3 .

The flow chart of the weight loss static immersion test is given in figure 3 . The process involves the preparation of specimens of $1.5 \mathrm{~cm} \times 1.5 \mathrm{~cm} \times 0.5 \mathrm{~cm}$ cross section from the friction stir weld zone, subsequently followed by metallographic polishing, acetone wash and air drying, and initial weighing of the specimens. Further, the specimens are immersed in $3.5 \mathrm{M} \mathrm{NaCl}$ solution for 24, 48, 72, 96 and $120 \mathrm{~h}$ duration. Subsequently, the specimens are subjected to cleaning and rinsing in tabulated. From, the weight loss, the Corrosion Rate (CR) is calculated in mils per year using equation 1.

Where

$$
\text { CorrosionRate }(C R)=\left(\frac{8.76 * 10^{4} * w}{\rho * A * t}\right)
$$

$$
\begin{array}{r}
\rho \text { is the density determined by the archimedes principle, } \\
\text { Aisthesurfaceareaof thespecimenincm }{ }^{2},
\end{array}
$$

tistheexposuretimeinh,

wistheweightlossing.

Further, the results are represented graphically for time duration of 24,48 , 72,96 , and $120 \mathrm{~h}$ respectively, and the comparisons drawn for each of the findings. 


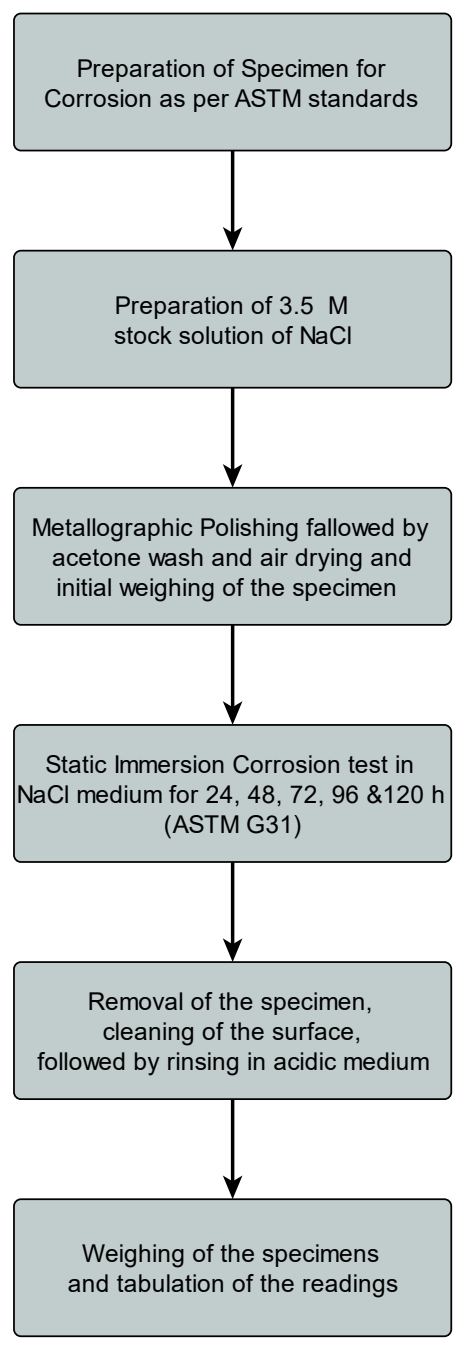

Fig. 3. Flow chart of the weight loss corrosion test

\section{$3 \quad$ Results and discussions}

The results of corrosion tests for FSW specimens are presented in this section. The observations clearly reveal that the corrosion rate decreases with the increase in rotational speed to $1200 \mathrm{rpm}$, feed to $140 \mathrm{~mm} / \mathrm{min}$ and for a tool offset of $-0.5 \mathrm{~mm}$. Further, the corrosion rate is minimum for friction stir welded joints using triangular pin profile. The experimental trials carried out in accordance with Taguchi's L9 orthogonal array and the specimen designation for each of the trials is given in table 4 . 
Table 4. Design of Experiments table

\begin{tabular}{cccccc}
\hline $\begin{array}{c}\text { E } \\
\text { xp. } \\
\mathrm{N} \\
\text { o. }\end{array}$ & $\begin{array}{c}\text { Rotational } \\
\text { Speed } \\
\text { (RPM) }\end{array}$ & $\begin{array}{c}\text { Feed( } \\
\mathrm{mm} / \mathrm{min})\end{array}$ & $\begin{array}{c}\text { Tool } \\
\text { Offset(mm) }\end{array}$ & $\begin{array}{c}\text { Tool Pin } \\
\text { Profile }\end{array}$ & $\begin{array}{c}\text { Specimen } \\
\text { Designati } \\
\text { on }\end{array}$ \\
\hline 1 & 800 & 100 & 0 & Cyl. & S1F1T1C \\
\hline 2 & 800 & 120 & 0.5 & Cyl.(Tp) & $\begin{array}{c}\text { S1F2T2C } \\
\text { T }\end{array}$ \\
\hline 3 & 800 & 140 & -0.5 & Tr. & S1F3T3T \\
\hline 4 & 1000 & 100 & 0 & Cyl. & S2F1T1C \\
\hline 5 & 1000 & 120 & 0.5 & Cyl.(Tp) & $\begin{array}{c}\text { S2F2T2C } \\
\text { T }\end{array}$ \\
\hline 6 & 1000 & 140 & -0.5 & Tr. & S2F3T3T \\
\hline 7 & 1200 & 100 & 0 & Cyl. & S3F1T1C \\
\hline 8 & 1200 & 120 & 0.5 & Cyl.(Tp) & $\begin{array}{c}\text { S3F2T2C } \\
\text { T }\end{array}$ \\
\hline 9 & 1200 & 140 & -0.5 & Tr. & S3F3T3T \\
\hline
\end{tabular}

\subsection{Corrosion Rate at a tool rotational speed of 800 RPM}

The Corrosion Rate (CR), for the specimens, friction stir welded at $800 \mathrm{rpm}$ is given in table 5, and the subsequent comparative graph is given in figure 4 . From, the table and the graph, it is evident that the corrosion rate decreases with time for different specimens, and the corrosion rate is minimum for triangular tool pin profile.

Table. 5 Corrosion Rate (CR) for different specimens at a rotational speed of 800 RPM

\begin{tabular}{cccc}
\hline $\begin{array}{c}\text { Time } \\
(\mathrm{h})\end{array}$ & $\begin{array}{c}\text { CR(mp } \\
\text { y) }\end{array}$ & $\begin{array}{c}\text { CR(mp } \\
\text { S1F1T1C }\end{array}$ & $\begin{array}{c}\text { CR(m } \\
\text { py) }\end{array}$ \\
\hline 24 & 7.19 & 6.77 & 6.36 \\
48 & 6.39 & 6.12 & 5.91 \\
72 & 5.82 & 5.68 & 5.55 \\
96 & 5.59 & 5.42 & 5.32 \\
120 & 5.48 & 5.37 & 5.26 \\
\hline
\end{tabular}




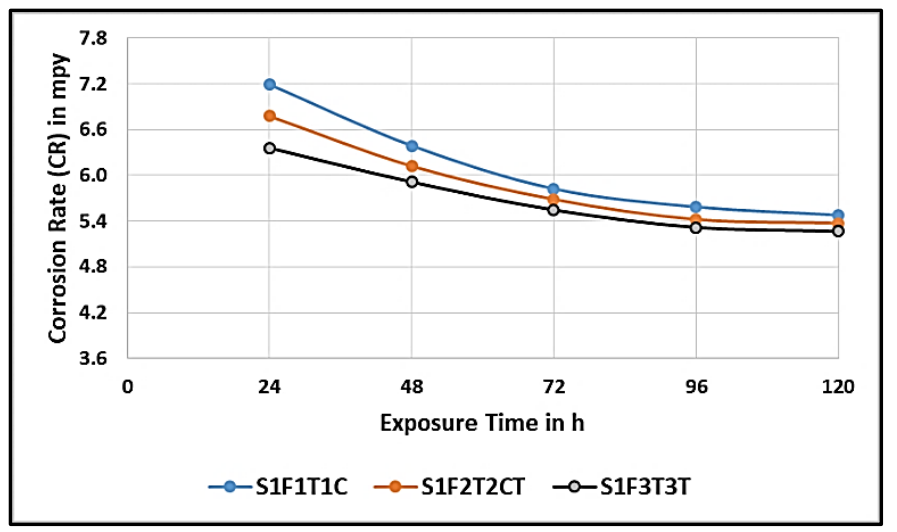

Fig. 4. CR for different specimens at 800 RPM

\subsection{Corrosion Rate at a tool rotational speed of 1000 RPM}

The Corrosion Rate (CR), for the specimens, friction stir welded at $1000 \mathrm{rpm}$ is given in table 6, and the subsequent comparative graph is given in figure 5. From, the table and the graph, it is evident that the corrosion rate decreases with time for different specimens, and the corrosion rate is minimum for triangular tool pin profile. Also, the corrosion rate decreases with the increase in tool rotational speed.

Table 6. Corrosion Rate (CR) for different specimens at a rotational speed of $1000 \mathrm{RPM}$

\begin{tabular}{cccc}
\hline $\begin{array}{c}\text { Time } \\
(\mathrm{h})\end{array}$ & $\begin{array}{c}\text { CR(mp } \\
\text { y) } \\
\text { S2F1T1C }\end{array}$ & $\begin{array}{c}\text { CR(mp } \\
\text { y) }\end{array}$ & $\begin{array}{c}\text { CR(m } 2 \text { T2CT } \\
\text { sy) }\end{array}$ \\
\hline 24 & 6.66 & 6.24 & 5.89 \\
48 & 6.06 & 5.85 & 5.29 \\
72 & 5.57 & 5.43 & 5.11 \\
96 & 5.33 & 5.23 & 4.98 \\
120 & 5.26 & 5.18 & 5.00 \\
\hline
\end{tabular}




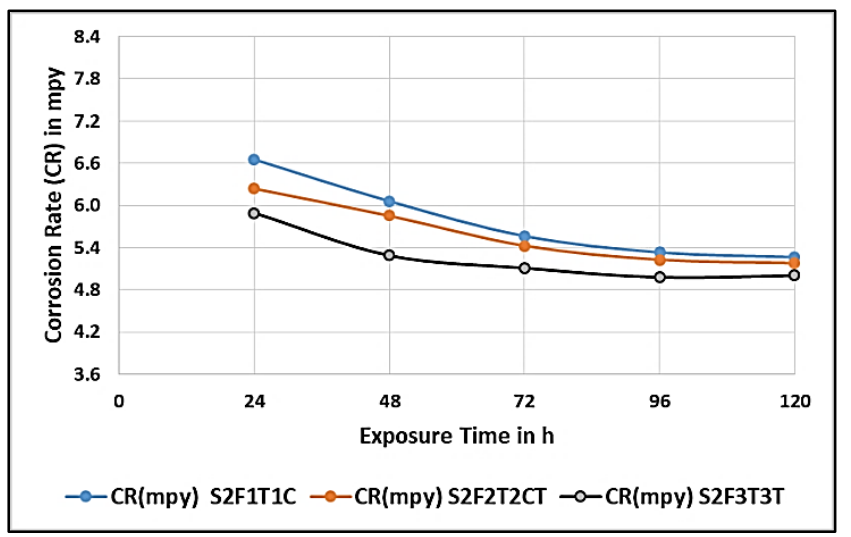

Fig. 5. CR for different specimens at 1000 RPM

\subsection{Corrosion Rate at a tool rotational speed of 1200 RPM}

The Corrosion Rate (CR), for the specimens, friction stir welded at $1200 \mathrm{rpm}$ is given in table 7 , and the subsequent comparative graph is given in figure 6. From, the table and the graph, it is evident that the corrosion rate decreases with time for different specimens, and the corrosion rate is minimum for triangular tool pin profile. Also, the corrosion rate decreases with the increase in tool rotational speed from $1000 \mathrm{rpm}$ to $1200 \mathrm{rpm}$.

Table 7. Corrosion Rate (CR) for different specimens at a rotational speed of $1200 \mathrm{RPM}$

\begin{tabular}{cccc}
\hline $\begin{array}{c}\text { Time } \\
(\mathrm{h})\end{array}$ & $\begin{array}{c}\text { CR(mp } \\
\text { y) } \\
\text { S3F1T1C }\end{array}$ & $\begin{array}{c}\text { CR(mp } \\
\text { y) }\end{array}$ & $\begin{array}{c}\text { CR(m } 2 \text { CT } \\
\text { py) }\end{array}$ \\
\hline 24 & 6.12 & 5.89 & 5.66 \\
48 & 5.85 & 5.32 & 4.93 \\
72 & 5.39 & 5.17 & 4.87 \\
96 & 5.21 & 5.03 & 4.86 \\
120 & 5.17 & 4.99 & 4.84 \\
\hline
\end{tabular}




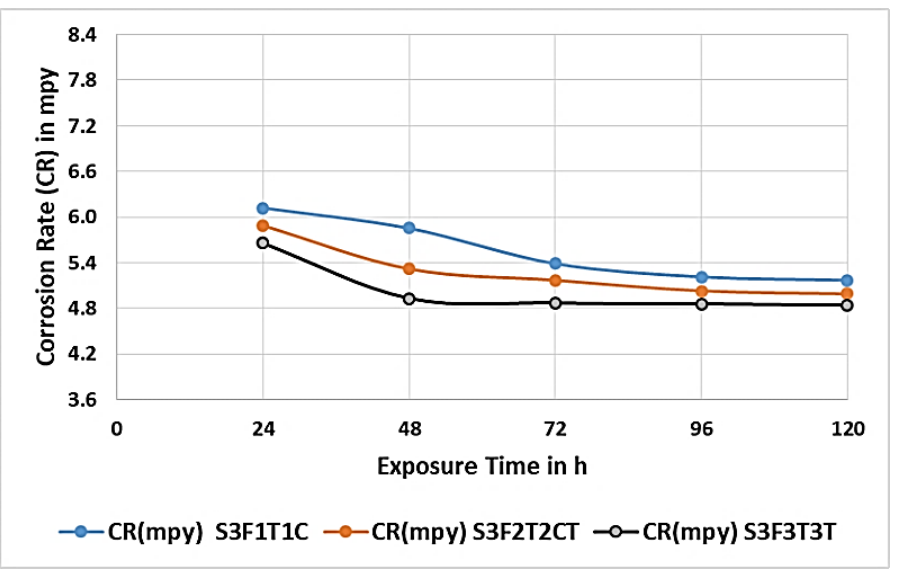

Fig. 6. CR for different specimens at 1200 RPM

The variation of corrosion rate for different process parameters are illustrated in graphs in figure 4, figure 5, and figure 6, respectively. Further, the surface morphology of the corroded surfaces is studied and the reason for the variation in corrosion rate is clearly understood through the microstructural examinations.

\subsection{Microstructure of Corroded Specimens}

The surface morphology of the corroded surfaces are studied and the reason for the variation in corrosion current and corrosion rate is clearly understood through the microstructural images in figure 7.The surface morphology of the corroded surfaces for specimens of experimental trial 1, experimental trial 5 and experimental trial 9 are given in figure 7(a), 7(b) and 7(c) respectively. The surface morphology of the corroded surface of the three different specimens captured at $200 x$, clearly reveals that there is corrosion pits and crevices which are predominant in the specimens friction stir weld at $800 \mathrm{rpm}$ (Figure 7 (a)), and as the rotational speed of friction stir welding is increased to $1000 \mathrm{rpm}$ and $1200 \mathrm{rpm}$, the corrosion rate decreases due to the formation of passive oxide film as in the specimen of experimental trial 5 (Figure 7 (b)) and subsequently a passive layer as in the specimen of experimental trial 9 (Figure 7 (c)). 


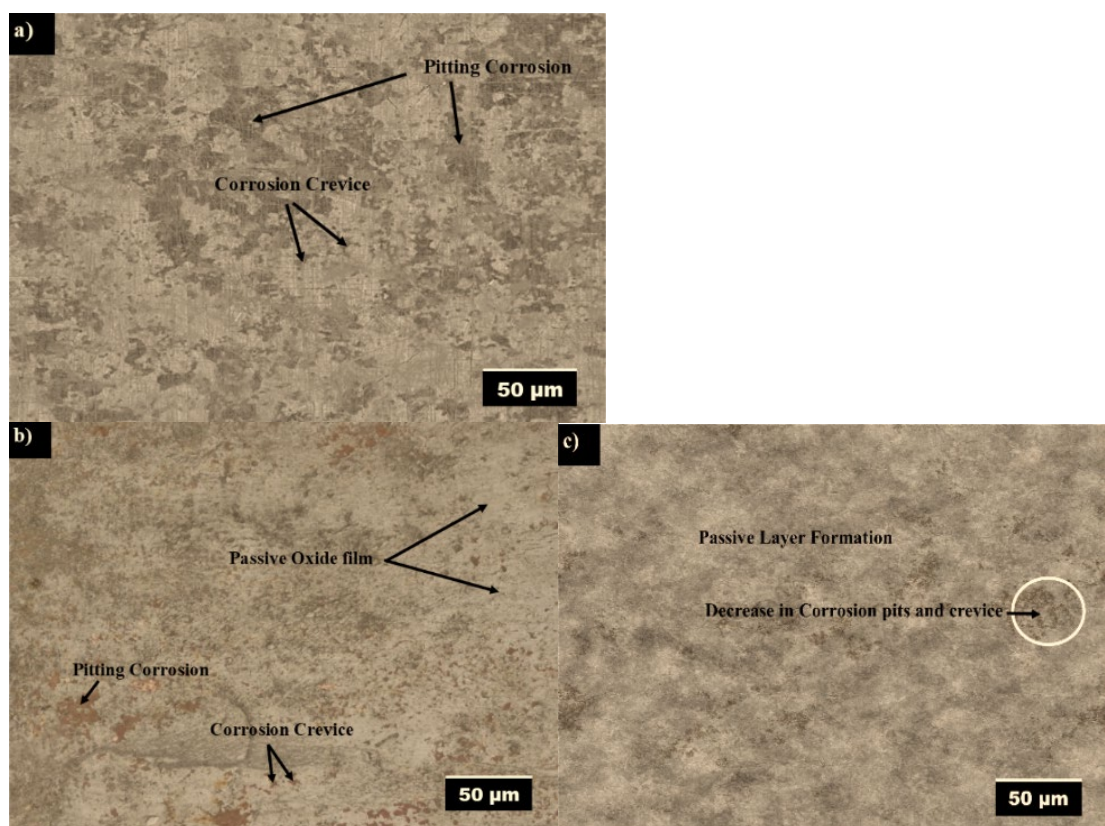

Fig. 7.Microstructural images of the surface morphology of the corroded surfaces of (a) Specimen of experimental trial 1, (b) Specimen of experimental trial 5, (c) Specimen of experimental trial 9.

\section{Conclusions}

From, the critical evaluation of the findings of the corrosion characterization, it is herewith seen that the corrosion resistance properties of the specimens increase with the increase in rotational speed, feed and for triangular tool pin profile and for tool offset of $-0.5 \mathrm{~mm}$. The corrosion rate decreases from $7.19 \mathrm{mpy}$ for tool rotational speed of $800 \mathrm{rpm}$, feed of $100 \mathrm{~mm} / \mathrm{min}$, cylindrical tool pin profile for $24 \mathrm{~h}$ duration to $4.84 \mathrm{mpy}$ for tool rotational speed of $1200 \mathrm{rpm}$, feed of $140 \mathrm{~mm} / \mathrm{min}$, triangular tool pin profile, for $120 \mathrm{~h}$ duration; this is majorly due to the formation of passive oxide layer at higher speed, feed and negative tool offset. The corrosion morphology depicted through the microstructure reveals that the passive layers are formed for friction stir weld specimens with the increase in feed, speed and use of triangle tool pin profile with $-0.5 \mathrm{~mm}$ tool offset, which eventually inhibits the formation of corrosion crevices and corrosion pits and corrosion rate decreases with time due to passivation over a period of time.

Further, the friction stir weld joint of dissmilar aluminium alloys is carried out with the potential of finding the alternative for development of a new fabrication technique to manufacture the structural components of MAV (Micro Air Vehicles) and UAV (Unmanned Air Vehicles) [8] to overcome the challenges especially related to better hardness and tensile strength. 


\section{References}

1. Jitender Kundu, Hari Singh, "Friction Stir Welding of Dissimilar AL alloys: Effect of process parameters on mechanical properties," Engineering Solid Mechanics, vol.4, pp.125-132, 2016.

2. Sadesh P, Venkatesh Kannan. M, Rajkumar V, Avinash. P, "Studies on Friction Stir welding of AA2024 and AA6061 dissimilar metals," Procedia Engineering, vol.75, pp.145-149, 2014.

3. H.M. Rao, "Effect of Process Parameters on Mechanical Properties of Friction Stir Spot Welded Magnesium to Aluminum Alloys," vol.15, pp.1-34, 2015.

4. Ramesha K, Sudersanan P. D, Santhosh. N, Ravichandran. G, Manjunath N, "Optimization of Friction Stir Welding Parameters Using Taguchi Method for Aerospace Applications. Advances in Structures, Systems and Materials," Lecture Notes on Multidisciplinary Industrial Engineering, Springer, Singapore, pp 293 -306, 2020.

5. Santhosh N, U. N. Kempaiah, Ashwin C Gowda, "Corrosion Characterization of Silicon Carbide and Fly Ash Particulates Dispersion Strengthened Aluminium 5083 Composites," Journal of Catalyst \& Catalysis, 4(2), pp 9-21, 2017.

6. Santhosh N, Kempaiah U. N, Ashwin C Gowda, Srilatha Rao, Gurumoorthy Hebbar, "Evaluation of Corrosion Mechanics of Silicon Carbide and Fly Ash Reinforced Hybrid Aluminium Metal Matrix Composites," International Conference on Emerging Research in Civil, Aeronautical \& Mechanical Engineering, pp 214 - 218, Nitte Meenakshi Institute of Technology, Bengaluru, India, July 212017.

7. Qin H, Zhang H, Sun D. et al "Corrosion behavior of the friction-stir-welded joints of 2A14-T6 aluminum alloy," Int J. Miner. Metall. Mater, 22, 627-638, 2015.

8. S. Jangam, S. Raja, and B. . Maheswar Gowd, "Influence of multiwall carbon nanotube alignment on vibration damping of nanocomposites," J. Reinf. Plast. Compos., vol. 35, no. 8, 2016.

9. S. T. Ahmed and K. K. Patil, "An investigative study on motifs extracted features on real time big-data signals," 2016 International Conference on Emerging Technological Trends (ICETT), Kollam, 2016, pp. 1-4, doi: 10.1109/ICETT.2016.7873721.

10. K. D. Singh and S. T. Ahmed, "Systematic Linear Word String Recognition and Evaluation Technique," 2020 International Conference on Communication and Signal Processing (ICCSP), Chennai, India, 2020, pp. 0545-0548, doi: 10.1109/ICCSP48568.2020.9182044

11. Gunashree, M., Ahmed, S. T., Sindhuja, M., Bhumika, P., Anusha, B., \&Ishwarya, B. (2020). A New Approach of Multilevel Unsupervised Clustering for Detecting Replication Level in Large Image Set. Procedia Computer Science, 171, 1624-1633. https://doi.org/10.1016/j.procs.2020.04.174 